\title{
Risk Factors for Speech Delay of Unknown Origin in 3-Year-Old Children
}

\author{
Thomas F. Campbell, Christine A. Dollaghan, Howard E. Rockette, Jack L. Paradise, Heidi M. Feldman, \\ Lawrence D. Shriberg, Diane L. Sabo, and Marcia Kurs-Lasky
}

\begin{abstract}
One hundred 3-year-olds with speech delay of unknown origin and 539 same-age peers were compared with respect to 6 variables linked to speech disorders: male sex, family history of developmental communication disorder, low maternal education, low socioeconomic status (indexed by Medicaid health insurance), African American race, and prolonged otitis media. Abnormal hearing was also examined in a subset of 279 children who had at least 2 hearing evaluations between 6 and 18 months of age. Significant odds ratios were found only for low maternal education, male sex, and positive family history; a child with all 3 factors was 7.71 times as likely to have a speech delay as a child without any of these factors.
\end{abstract}

The acquisition of intelligible speech is a striking developmental achievement of the preschool years. Clinically significant deficits in hearing, intelligence, or oral motor function are often accompanied by abnormal speech acquisition, but significant deficits in speech development also occur in children with normal hearing and intelligence and without frank sensorimotor or neurological disabilities. Such developmental phonological disorders of unknown origin have been labeled speech delay when they occur in children who are still in the developmental period of speech acquisition, that is, from 2 years, 0 months to 8 years, 11 months (Shriberg, 1980). Speech delay is diagnosed when the child's conversational speech sample either is more unintelligible than would be expected for his or her age or is characterized by speech sound error patterns not appropriate for his or her age (Shriberg, 1993; Shriberg, Austin, Lewis, McSweeny, \& Wilson,

Thomas F. Campbell and Christine A. Dollagham, Department of Communication Science and Disorders, University of Pittsburgh; Howard E. Rockette, Department of Biostatistics, University of Pittsburgh; Jack L. Paradise and Heidi M. Feldman, Department of Pediatrics, University of Pittsburgh; Lawrence D. Shriberg, Department of Communicative Disorders, University of Wisconsin-Madison; Diane L. Sabo; Department of Communication Science and Disorders, University of Pittsburgh; Marcia KursLasky, Department of Biostatistics, University of Pittsburgh.

This work was supported by grant HD26026 from the National Institute for Child Health and Human Development and the Agency for Health Care Policy and Research, and by grants DC0368 and DC00496 from the National Institute of Deafness and other Communication Disorders, and by gifts from GlaxoSmithKline and Pfizer Inc. We are indebted to the pediatricians at our several study sites who have provided support for the study. We also wish to thank staff team members Dayna Pitcairn, D. Kathleen Colborn, and Clyde G. Smith as well as phonetic transcription team members Robert Allen, Kristen Dambach, Tara Jackson, Sheryl Kaufhold, Tonia Sacca, Gina Shongo, Beth Simari, James White, and Jean Robbins for their assistance in completing this study.
1997). According to a recent epidemiological study by Shriberg, Tomblin, and McSweeny (1999), the prevalence of speech delay in 6-year-old children is $3.8 \%$. Its prevalence in younger children has not been reported previously, but those investigators suggested that approximately $14 \%$ of 3 -yearold children would meet the criteria for speech delay.

Although the etiology of speech delay is currently unknown, many variables have been described as potential risk factors based on correlational or group mean comparison studies (Shriberg \& Kwiatkowski, 1994). Among the most frequently mentioned variables are male sex, factors associated with socioeconomic disadvantage, family history of developmental speech-language disorder, and persistent otitis media (OM). For example, Shriberg et al.'s (1999) study of 6-year-olds found that speech delay was more prevalent in boys than in girls, more prevalent in children from urban than from suburban or rural areas, and more prevalent in African American than in White children. Those findings are consistent with the findings of several earlier studies reporting variously that male sex (e.g., Silva, Justin, McGee, \& Williams, 1984) and variables linked to socioeconomic disadvantage, including low socioeconomic status (e.g., Lassman, Fisch, Vetter, \& LaBenz, 1980), low parental educational level (e.g., Winitz \& Darley, 1980), and minority race (e.g., Fujiura \& Yamaki, 2000) were associated with rate of speech development. A history of developmental speech-language disorder in a first-degree relative has also been linked to speech delay in several studies (e.g., Felsenfeld, McGue, \& Broen, 1995; Lewis, Ekelman, \& Aram, 1989; Shriberg, 1994; Tomblin, Hardy, \& Hein, 1991). Finally, as reviewed

(C) 2003 by the Society for Research in Child Development, Inc. All rights reserved. 0009-3920/2003/7402-0002 
recently by Shriberg, Flipsen, et al. (2000), persistent otitis media with effusion (OME), which is often associated with variably elevated hearing thresholds, has been found to correlate with impaired speech development in some studies (e.g., Silva, Chalmers, \& Stewart, 1986; Teele, Klein, Chase, Menyuk, \& Rosner, 1990) but not in others (e.g., Harston, Nettelbladt, Schalen, Kalm, \& Prellner, 1993; Paradise et al., 2000; Paradise et al., 2001; Roberts, Burchinal, Koch, Footo, \& Henderson, 1988).

Although correlational and group comparison studies such as those described previously can suggest which variables may be associated with speech delay, they provide no information on the extent to which the presence of a variable actually increases a child's risk of the condition or the potential effects of reducing exposure to the risk variable (Scott, Mason, \& Chapman, 1999). Such evidence requires the use of measures such as the risk ratio, the odds ratio, the population-attributable fraction, and the number needed to treat (Scott et al., 1999; Streiner, 1998; Zhang \& Wu, 1998). Of the variables mentioned earlier, only two-persistent OME and the conductive hearing loss that often accompanies it-have been studied using such measures. Based on relative risk indices, Shriberg, Flipsen, et al. (2000) and Shriberg, Friel-Patti, Flipsen, and Brown (2000) found that neither OME nor an abnormal hearing test between 6 and 18 months of age increased the risk of clinically defined speech delay at age 3 years, although those factors were associated with increased risk of lower performance on certain speech measures in certain cohorts of children. Noting that the 95\% confidence intervals for these risk estimates were wide, the authors urged caution in interpreting or generalizing these risk estimates and pointed out the need for larger samples in which potentially confounding sociodemographic variables are also measured.

In the present study, we calculated odds ratios in a large, diverse sample of children to determine whether 3-year-olds with speech delay of unknown origin had significantly higher odds of having any of six potential risk factors: male sex, low maternal educational level, low socioeconomic status, African American race, a history of developmental communication disorder in a first-degree relative, and persistent OM. In addition, in a smaller subgroup of children who had received at least two hearing evaluations between 6 and 18 months of age, we calculated the odds that children with speech delay of unknown origin had at least two abnormal hearing tests. Finally, in addition to examining the odds of exposure to the individual risk factors we also calculated the odds of aggregated risk exposure. This study is among the first to estimate quantitatively the relative impact of variables that have long been associated with speech delays of unknown origin in correlational and group comparison studies.

\section{Method}

\section{Participants}

Participants were 639 children who were 3 years old and were being followed in a larger, prospective study of persistent OM in relation to children's development (Paradise et al., 2000; Paradise et al., 2001). The larger study involved both a randomized clinical trial and a nontrial, associational component. A large, sociodemographically diverse group of apparently healthy infants was enrolled by age 2 months from two urban, two small town or rural, and four suburban primary care practices in the Pittsburgh, Pennsylvania, area. Infants were excluded who met any of the following criteria: (a) birth weight less $5 \mathrm{lb}(2,268 \mathrm{~g})$; (b) small for gestational age; (c) a history of neonatal asphyxia or other serious illness; (d) multiple birth; (e) in foster care or adopted; $(\mathrm{f})$ mother younger than 18 years; (g) mother seriously ill or dead; (h) mother known to be a drug or alcohol abuser or, in the judgment of study personnel, too limited socially or intellectually to give informed consent or adhere to the study protocol. Children were also excluded if a language other than English was spoken at home, if a sibling was participating in the study, or if their parents planned to move from the region within 5 years.

Figure 1 summarizes schematically the derivation of the participants in the present study. The 6,350 children initially enrolled in the study were monitored at least monthly beginning at 2 months of age. Those who met specified criteria regarding the cumulative duration of $\mathrm{OM}$ within the first 3 years of life (e.g., 90 days of continuous bilateral OM or 135 days of continuous unilateral $\mathrm{OM}$ ) were enrolled in a randomized clinical trial comparing the developmental effects of prompt and delayed tympanostomy tube placement. A total of 429 children were assigned randomly in this trial, 402 of whom underwent developmental testing at age 3 years (see Paradise et al., 2001, for details). From among the large number of children whose OM duration did not qualify them for this randomized trial group, 


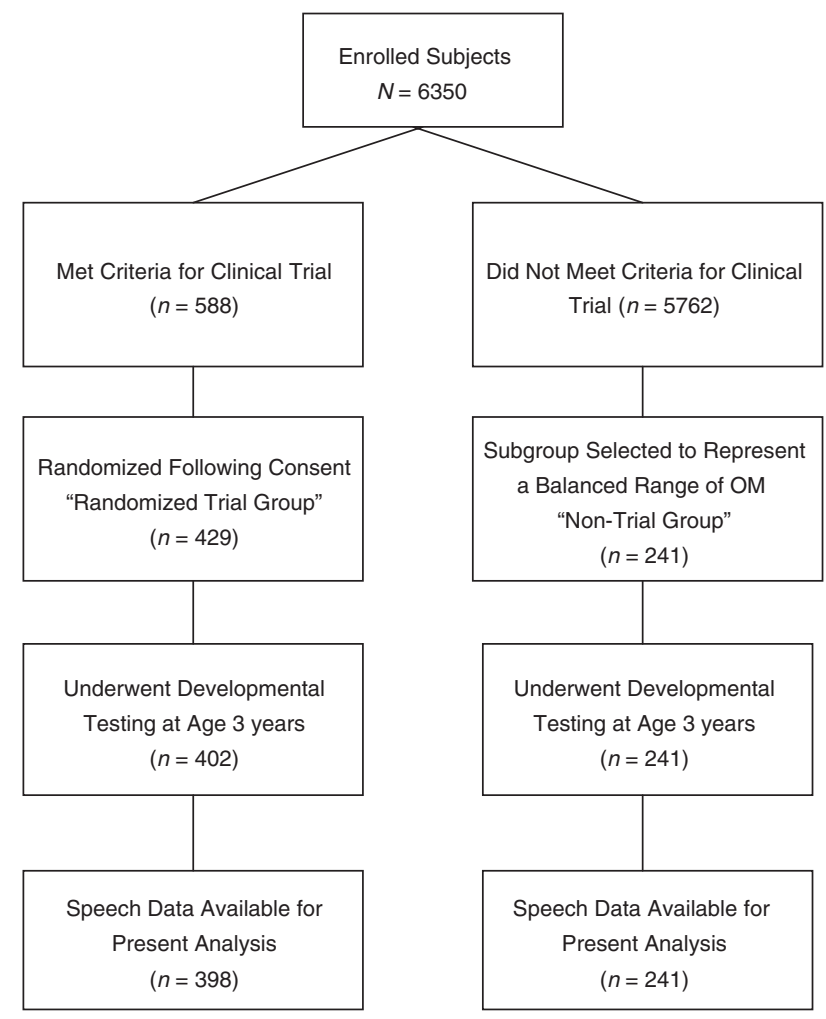

Figure 1. Derivation of the 639 participants in the present study. we selected randomly, within balanced sociodemographic strata, a nontrial sample of 241 children who represented a spectrum of $\mathrm{OM}$ experience from having no $\mathrm{OM}$ to having $\mathrm{OM}$ whose cumulative duration fell just short of meeting randomization criteria (see Paradise et al., 2000, for details). All 241 children in the nontrial group underwent developmental testing at age 3 years.

Because of equipment malfunction, data from speech assessments were not available for 4 participants in the randomized trial group, leaving a total of 639 participants (398 from the randomized trial group and 241 from the nontrial group) available for the present investigation of risk factors and speech delay. Table 1 summarizes the sociodemographic characteristics of the children in the randomized trial and the nontrial groups. Consistent with the manner in which the groups were derived, the randomized trial group had a higher mean cumulative percentage of days with OM (39.2\%) than did the nontrial group $(15.5 \%)$.

\section{Measurement of Risk Variables}

Sociodemographic variables. At the time of enrollment in the study, a standardized medical and social history was obtained from each child's parent or guardian. This questionnaire provided data on the child's sex, the family's health insurance status

Table 1

Percentage of Participants in the Randomized Trial $(N=398)$ and Nontrial $(N=241)$ Groups Having Each Characteristic

\begin{tabular}{|c|c|c|}
\hline \multirow[b]{2}{*}{ Characteristic } & \multicolumn{2}{|c|}{ Group } \\
\hline & Randomized trial & Nontrial \\
\hline \multicolumn{3}{|l|}{ Maternal education level ${ }^{a}$} \\
\hline Less than high school graduate & 12.8 & 9.9 \\
\hline High school graduate & 79.6 & 69.5 \\
\hline College graduate & 7.5 & 20.4 \\
\hline \multicolumn{3}{|l|}{ Sex } \\
\hline Male & 57.3 & 49.8 \\
\hline Female & 42.7 & 50.2 \\
\hline \multicolumn{3}{|c|}{ History of developmental communication disorder } \\
\hline In $\geq 1$ immediate family member & 28.1 & 24.9 \\
\hline In no immediate family members & 71.9 & 75.1 \\
\hline \multicolumn{3}{|l|}{ Health insurance ${ }^{b}$} \\
\hline Medicaid & 65.1 & 32.5 \\
\hline Private & 34.9 & 67.5 \\
\hline \multicolumn{3}{|l|}{ Race $^{c}$} \\
\hline African American & 38.5 & 16.4 \\
\hline White & 61.5 & 83.6 \\
\hline
\end{tabular}

${ }^{\mathrm{a}}$ Not reported for 1 child. ${ }^{\mathrm{b}}$ None reported for 7 children. ${ }^{\mathrm{c}}$ Neither race reported for 14 children. 
(private insurance or Medicaid) as an estimate of family socioeconomic status, and the highest level of education completed by the child's mother. Study personnel estimated the child's race based on observable physical characteristics of the child and the parent(s). Sex, health insurance type, maternal educational level, and race were treated as binary variables, with male sex, Medicaid health insurance, failure of the child's mother to complete high school, and African American race coded as positive risk variables.

Family history. A questionnaire adapted from Tomblin (1989) was used to solicit information concerning the presence of developmental communication disorders in each of the child's first-degree relatives. The questionnaire solicits information on stuttering as well as on developmental articulation and language disorders, which are described as difficulties in the pronunciation of speech sounds in words and in the development of vocabulary and sentence structure. The child's parent or guardian completed this questionnaire at the developmental testing session when the child was 3 years old. Family history was treated as a binary risk variable, coded as positive if a developmental communication disorder (i.e., stuttering, developmental articulation disorder, or developmental language disorder) was reported in at least one of the child's first-degree relatives.

$O M$. Cumulative duration of OM (including OME as well as the middle-ear effusion associated with acute OM) during the first 3 years of life was estimated based on findings from pneumatic otoscopic evaluations for children who obtained at least monthly evaluations between 2 and 36 months of age. For each child, we estimated the cumulative percentage of days on which unilateral and bilateral $\mathrm{OM}$, respectively, were present, using interpolation rules described by Paradise et al. (1997). In one odds ratio analysis, the cumulative percentage of days with $\mathrm{OM}$ in the first 3 years of life was treated as a continuous variable. In a second analysis designed to examine potential threshold effects, the percentage of days with $\mathrm{OM}$ was classified into seven categories defined by 5\% increments, namely, $\geq 19.5 \%, \geq 24.5 \%, \geq 29.5 \%, \geq 34.5 \%, \geq 39.5 \%$, $\geq 44.5 \%$, and $\geq 49.5 \%$. Cumulative OM duration exceeding or not exceeding each of these levels was then treated as a binary variable for another set of odds ratio analyses.

Hearing. Hearing evaluations were scheduled for individual children when they had experienced 8 continuous weeks of unilateral or bilateral OM, every 4 weeks thereafter while OM persisted, and once OM had resolved. All audiometric testing was performed in an acoustically shielded sound suite using Grason-Stadler GSI 16 or Beltone 2000 audiometers. In a subset of children who had received at least two hearing evaluations between 6 and 18 months of age, we analyzed for the presence or absence of abnormal hearing using three threshold cutoff levels: $\geq 20 \mathrm{~dB}, \geq 25 \mathrm{~dB}$, and $\geq 30 \mathrm{~dB}$. Hearing levels were defined as the pure tone average of at least three of the four frequencies tested (i.e., 0.5, 1, 2, and $4 \mathrm{kHz}$ ). Because the study's protocol did not include routine audiometric testing for children with lesser durations of $\mathrm{OM}$ than those specified earlier, most of the children in the nontrial group did not receive two hearing evaluations during this age period. Therefore, odds ratios for the three levels of abnormal hearing were calculated only for the 279 children from the randomized trial group who received at least two hearing evaluations between 6 and 18 months of age.

\section{Testing Procedures}

Children participated individually in a testing session at the Children's Hospital of Pittsburgh at 36 to 38 months of age. Examiners were blinded to children's family history of developmental communication disorders, maternal education level, OM experience, and health insurance status. The testing session lasted approximately $2 \mathrm{hr}$ and included the administration of standardized and nonstandardized measures required to answer the research questions of the larger study. Every effort was made to ensure that testing occurred only if the child's bilateral hearing thresholds earlier that day met specified criteria. For children whose hearing was tested by means of earphones, criteria were hearing thresholds in each ear of $\leq 15 \mathrm{~dB}$ at 1,2 , and $4 \mathrm{kHz}$. For children tested in the sound field, criteria were thresholds of $\leq 25 \mathrm{~dB}$ at 0.5 , and $\leq 20 \mathrm{~dB}$ at 1,2 , and $4 \mathrm{kHz}$. Whenever possible, children who failed to meet these hearing criteria were scheduled for retesting at a later date no more than 2 months after their third birthday. When retesting was not feasible, or when children failed the hearing test at or near the end of the 2-month developmental testing period, developmental testing was undertaken without further delay.

After the hearing test, as part of the developmental testing protocol, a continuous speech sample approximately $15 \mathrm{~min}$ long was audiorecorded during play with a set of toys (including kitchen utensils, food items, appliances, and a miniature playhouse with vehicles, furniture, and people) that 
was available to all participants. Caregivers familiar to the child were present during the speech sampling sessions; the examiner was also present during a small number of the sessions in which the parent requested assistance. Caregivers were instructed to "play and talk with your child as you would at home, so that we can get an idea of your child's speech and language skills." Speech samples were recorded using a portable audiocassette recorder (Marantz PMD 201) and both a wireless FM (Telex WT-25) and a tabletop microphone (Radio Shack PZM).

\section{Transcription and Analysis of Continuous Speech} Samples

Speech analyses were conducted on consecutive utterances in the 15-min speech sample until the criterion of identifying the first 100 first-occurrence words (i.e., word types) was met. Trained research assistants who were blinded to all participant information transcribed the words phonetically using the transcription consensus procedures described by Shriberg, Kwiatkowski, and Hoffman (1984). Each transcriber had completed both a graduate level course in phonetic transcription and advanced training in phonemic and phonetic transcription. The data were then analyzed by computer using Programs to Examine Phonetic and Phonologic Evaluation Records (PEPPER; Shriberg, Allen, McSweeny, \& Wilson, 2000) to yield summary speech statistics.

\section{Transcription Reliability}

To calculate phonetic transcription reliability, 64 conversational speech samples (10\% of the 639 participants) were randomly selected and transcribed independently by a second research assistant to determine intertranscriber agreement for both broad and narrow transcription. The phoneme-byphoneme percentage of agreement was $92 \%$ for broad transcription and $86 \%$ for narrow transcription. These transcription reliability estimates are comparable to those reported in other studies of normal and disordered child phonology (McSweeny \& Shriberg, 1995; Shriberg et al., 1999).

In addition, because the percentage of unintelligible words also was a criterion for speech delay, intertranscriber agreement for identifying unintelligible words was assessed. Conversational speech samples of 10 randomly selected children with speech delay $(10 \%$ of the sample of children with speech delay) were transcribed independently by a second research assistant. Transcribers used intonational contours and perceptual word-boundary timing cues to determine whether the child's unintelligible productions were monosyllabic or disyllabic. Point-to-point agreement was 93\% for coding unintelligible words; the reliability coefficient for Intelligibility Index scores between the two independent transcribers was $r=.98$.

\section{Definition of Speech Delay}

The Speech Disorders Classification System (SDCS), a well-developed diagnostic system (Shriberg, 1993; Shriberg et al., 1997), was used to identify children with speech delay of unknown origin. The SDCS is age referenced, with classification criteria for speech delay differing for each of eight age groups. The SDCS classifies a 3-year-old child as having speech delay if a transcriber can gloss $75 \%$ or fewer of the words in a continuous speech sample, or if the speech sample contains errors not expected of a 3-year-old child (e.g., not producing the bilabial consonants $/ \mathrm{p}, \mathrm{b}, \mathrm{m} /$ in the initial position of words; see Shriberg, 1993, pp. 132-140, for a detailed list of SDCS criteria by age.) Our decision to use a single, binary measure of speech outcome (i.e., speech delayed or not speech delayed) was motivated by the validity, reliability, and clinical utility of the speech delay metric (cf. Shriberg et al., 1997) and by a desire to examine risk variables in children whose speech-production skills clearly fall outside the normal range.

\section{Analyses}

Odds ratio analyses were conducted to compare the probability that children with and without speech delay of unknown origin had been exposed to the seven risk factors as defined earlier. The odds ratio is one of several risk indices, all of which reflect the probability that an individual will develop a particular outcome (Streiner, 1998). The odds ratio was used in the present investigation both because it is based on a case-control perspective in which individuals are separated according to a positive or a negative outcome and then examined for differential rates of prior exposure, and because it is preferred when more than one risk factor is under investigation (Walter, 2000).

The numbers of children diagnosed with and without speech delay who had each of the risk variables described previously were tabulated. For all binary risk variables, odds ratios were estimated using unconditional logistic regression. For the 
analysis in which the percentage of days with OM was treated as a continuous variable, a linear association of the percentage of time with $\mathrm{OM}$ and speech delay was tested.

A logistic regression model was also used to test for the effect of a risk variable after adjustment for the remaining independent variables and to test for possible interactions among variables related to speech delay. Hearing could not be included in this analysis because hearing data were not available for the entire sample. Alpha was set at $p<.05$ for all odds ratio calculations, and the $95 \%$ confidence intervals of the ratios were also calculated.

\section{Results}

To determine whether the randomized trial group and the nontrial group could be combined to increase statistical power, two preliminary analyses were conducted. We first investigated whether odds ratios for the risk variables differed between the two groups by including an indicator variable that identified whether observations were from the randomized trial group or the nontrial group and testing for interactions between group identity and risk variables. Hearing status was not included in this analysis because the requisite numbers of audiological evaluations were available only for participants in the randomized trial group. Results showed that there were no statistically significant interactions between any risk variable and study group; $p$ values for these tests ranged from .21 for family history to .86 for percentage of days with OM. We also verified that the percentage of children with speech delay in the randomized trial group (16.6\%) did not differ significantly from that in the nontrial group $(14.1 \%), \chi^{2}=0.52, p=.47$. Based on the results of these analyses, we combined the groups to perform the odds ratio analyses for all variables except abnormal hearing, which we analyzed only in children with the requisite number of hearing tests as described earlier.

\section{Individual Risks for Speech Delay}

Of the 639 participants in the combined sample, $100(15.6 \%)$ met the criteria for speech delay and 539 $(84.4 \%)$ did not. Table 2 shows the number and percentage of children with and without speech delay who had each of the binary risk variables, the corresponding unadjusted odds ratios (OR), and their 95\% confidence intervals. Four variablesnamely, low maternal education $(\mathrm{OR}=2.58)$, male sex $(O R=2.19)$, positive family history of developmental communication disorder $(\mathrm{OR}=1.67)$, and Medicaid health insurance $(\mathrm{OR}=1.59)$ - had statistically significant odds ratios; African American race was not a significant risk factor.

Odds ratios for OM were calculated only for children who had no gaps in monthly otoscopic evaluations from 2 to 36 months; $87 \%$ of the group with speech delay and $90.7 \%$ of group without speech delay met this criterion. The average cumulative percentage of days with $\mathrm{OM}$ during this period was similar in the two groups $(30.7 \%$ and $29.1 \%$ in the group with and the group without speech delay, respectively), and the resulting odds ratio for $\mathrm{OM}$ treated as a continuous variable was not significant $(\mathrm{OR}=1.01,95 \% \mathrm{CI}=0.99,1.02)$. In the additional analysis of possible threshold effects in which the cumulative percentage of days with $\mathrm{OM}$ from 2 to 36 months was categorized in 5\% increments from $\geq 19.5 \%$ to $\geq 49.5 \%$, a significant odds ratio $(\mathrm{OR}=1.73, p<.05)$ was found for the second highest category of OM duration $(\geq 44.5 \%$ of days). However, the $95 \%$ confidence interval for this

Table 2

Risk Variable Percentages by Speech Diagnosis, Associated Odds Ratios (OR), and Confidence Intervals (CI)

\begin{tabular}{lcccc}
\hline & Speech delay $(N=100)$ & No speech delay $(N=539)$ & \\
\cline { 2 - 3 } Risk variable & $\%$ & $\%$ & OR & $95 \%$ CI \\
\hline Low maternal education $^{\mathrm{a}}$ & $22 \%$ & $10 \%$ & $2.58^{* * *}$ & $1.49,4.48$ \\
Male sex & $70 \%$ & $52 \%$ & $2.19^{* *}$ & $1.38,3.47$ \\
Positive family history $^{\mathrm{b}}$ & $36 \%$ & $25 \%$ & $1.67^{*}$ & $1.06,2.62$ \\
Medicaid health insurance $^{\mathrm{c}}$ & $63 \%$ & $51 \%$ & $1.59^{*}$ & $1.02,2.49$ \\
African American race $^{\mathrm{d}}$ & $38 \%$ & $29 \%$ & 1.53 & $0.99,2.39$ \\
\hline
\end{tabular}

${ }^{a}$ Mother not a high school graduate; maternal education not reported for 1 child without speech delay. ${ }^{\mathrm{b}}$ Developmental communication disorder in $\geq 1$ first-degree relative. ${ }^{\mathrm{c}}$ No health insurance reported for 4 children with speech delay and 3 children without speech delay. ${ }^{\mathrm{d}}$ Race reported as neither White nor African American for 14 children without speech delay. ${ }^{*} p<.05 .{ }^{* *} p<.001$. 
Table 3

Number and Percentage of Children With Abnormal Hearing at Each Level, Associated Odds Ratios (OR), and Confidence Intervals (CI)

\begin{tabular}{|c|c|c|c|c|c|c|c|}
\hline \multirow[b]{2}{*}{ Hearing level } & \multicolumn{2}{|c|}{ Speech delay $(N=46)$} & \multicolumn{2}{|c|}{ No speech delay $(N=233)$} & \multirow[b]{2}{*}{ OR } & \multirow[b]{2}{*}{$95 \% \mathrm{CI}$} & \multirow[b]{2}{*}{$p$} \\
\hline & No. & $\%$ & No. & $\%$ & & & \\
\hline$\geq 20 \mathrm{~dB}$ & 36 & $78 \%$ & 165 & $71 \%$ & 1.48 & $0.70,3.16$ & .31 \\
\hline$\geq 25 \mathrm{~dB}$ & 18 & $39 \%$ & 79 & $34 \%$ & 1.25 & $0.65,2.40$ & .50 \\
\hline$\geq 30 \mathrm{~dB}$ & 9 & $20 \%$ & 49 & $21 \%$ & 0.91 & $0.41,2.02$ & .82 \\
\hline
\end{tabular}

Note. Includes only children from the randomized trial group with two or more hearing evaluations from 6 to 18 months.

odds ratio $(0.98,2.95)$ included 1.0 , suggesting that this apparent elevation in risk should be interpreted cautiously.

Table 3 shows the number and percentage of children with and without speech delay who had pure tone averages that were $\geq 20 \mathrm{~dB}, \geq 25 \mathrm{~dB}$ or $\geq 30 \mathrm{~dB}$ in two or more tests between 6 and 18 months of age. The unadjusted odds ratios and corresponding 95\% confidence intervals for each hearing level are also shown. None of the odds ratios was significantly greater than 1.0.

\section{Adjusted Odds Ratios}

To examine the impact of each putative individual risk factor while controlling for the others, we fitted a multivariate logistic regression model including maternal education, sex, family history, health insurance, race, and percentage of days with $\mathrm{OM}$ to the data. After these adjustments, the magnitude and significance of the odds ratios for low maternal education, male gender, and a family history of developmental communication disorder remained virtually unchanged, but Medicaid health insurance was no longer a significant risk. It is important to note, however, that maternal education and health insurance had a high degree of colinearity in the model, a fact that could result in instability in the estimates of the individual parameters of the model. We examined each parameter and the corresponding standard error for the various combinations of variables used in our multivariate modeling and found no evidence of model instability. Nonetheless, the colinearity between health insurance type and maternal educational level complicates efforts to specify their independent contributions to elevating the risk of speech delay.

The sole significant odds ratio for percentage of days with OM treated as a categorical variable $(\geq 44.5 \%)$ was no longer significant after adjusting for maternal education, sex, and family history of developmental communication disorder.

\section{Aggregated Risk for Speech Delay}

The odds ratio for speech delay was also calculated for the presence of the three factors with the largest individual odds ratios, that is, low maternal educational level, male sex, and a family history of developmental communication disorder. For a child with all of these factors, the aggregated odds ratio was $7.71(95 \% \mathrm{CI}=2.62,22.74)$; the area under the receiver operating characteristic (ROC) curve associated with the logistic regression model was .65. The area under the ROC curve can be interpreted as an estimate of the probability that the algorithm associated with the logistic regression model will correctly select the child with speech delay in a randomly selected pair of children from the data set where one child from the pair has speech delay and the other child does not.

As mentioned earlier, the maternal education and insurance status variables had high colinearity. We gave preference to maternal education in the aggregate analysis because its odds ratio (2.58, $\mathrm{CI}=1.49$, 4.48) was larger than that for health insurance type $(\mathrm{OR}=1.59, \mathrm{CI}=1.02,2.49)$. However, a logistic regression model in which type of insurance is substituted for mother's education also had a significant, though lower, aggregated odds ratio of 6.24 (95\% CI $=1.53,25.31)$. These results suggest that low maternal education and Medicaid health insurance may be proxies for low socioeconomic status in this sample of children.

\section{Discussion}

We examined seven variables that have been associated with speech delay in 3-year-old children. 
Four of these variables - mother not having completed high school, male sex, a family history of developmental communication disorder, and Medicaid health insurance - had odds ratios significantly greater than 1.0, and odds ratios for the first two variables exceeded 2.0, a threshold that has been suggested to represent a clinically significant elevation of risk (Sackett, Haynes, Guyatt, \& Tugwell, 1991; Streiner, 1998). The aggregated odds ratio for the three risk factors with the largest individual odds ratios (low maternal education, male sex, and positive family history) was 7.71 . Three variables -African American race, cumulative duration of OM from 2 to 36 months of age, and two abnormal hearing tests from 6 to 18 months of age-were not associated with increased risk of speech delay of unknown origin.

\section{$O M$ and Hearing Loss}

Whether treated as a continuous or a categorical variable, persistent $\mathrm{OM}$ in the first 3 years of life did not significantly increase the risk of speech delay after controlling for relevant covariates. The odds ratio for the cumulative percentage of days with $\mathrm{OM}$ was 1.01, with a narrow $95 \%$ confidence interval, and the percentages of days with $\mathrm{OM}$ in the groups with and without speech delay were similar (31\% and 29\%, respectively). These findings are consistent with evidence from several other recent studies in which no statistically significant relationships between duration of OM and speech-sound production skills were found (Paradise et al., 2000; Paradise et al., 2001; Roberts et al., 1988; Shriberg, Flipsen, et al., 2000). It is conceivable that cumulative durations of $\mathrm{OM}$ exceeding those we studied might increase the risk of speech delay, but few children would be expected to experience $\mathrm{OM}$ for longer durations than those studied here.

In the subset of children from the randomized trial group who had at least two hearing evaluations between 6 and 18 months of age, abnormal hearing was likewise not found to increase the risk of speech delay, even at thresholds as high as $30 \mathrm{~dB}$. The lack of a significant elevation in risk of clinical speech delay is consistent with evidence reported by Shriberg, Friel-Patti, et al. (2000), although those investigators found that an abnormal hearing test between 12 and 18 months of age was associated with significantly poorer performance on five of nine individual measures derived from continuous speech samples. Because both studies included relatively small numbers of children with abnormal hearing, findings should be interpreted cautiously.
Studies of larger samples in which other hearingrelated variables can be examined (e.g., frequency, duration, and severity of hearing deficits as well as the ages at which they occur) are needed to address fully the question of the relationship between intermittent conductive hearing loss associated with $\mathrm{OM}$ and speech development.

\section{Sex, Family History, and Maternal Educational Level}

Estimates of risk for speech delay of unknown origin associated with male sex, low maternal education, and a family history of developmental communication disorder have not previously been reported. However, findings from the present investigation showing that these variables significantly increase the risk of early speech delay are consistent with evidence from correlational and group comparison studies reporting differences in the speech production and language abilities of children according to sex (Leske, 1981; Lewis, 1992; Lewis et al., 1989; Shriberg et al., 1999; Winitz \& Darley, 1980), family history of developmental communication deficits (Lewis, 1992; Tomblin, 1989; Tomblin et al., 1991), and other sociodemographic variables (Dollaghan et al., 1999; Lassman et al., 1980; Paradise et al., 2000; Paradise et al., 2001).

The pathways by which each of these significant risk variables influences speech delay cannot be determined from the present study. However, these findings do provide directions for future research concerning the biologic, familial, and sociodemographic mechanisms that may underlie speech delay of unknown origin in preschool children. One question concerns the factors underlying the high ratio of boys to girls with speech delay at age 3 years. In the present study, $70 \%$ of the 100 children with speech delay were male and $30 \%$ were female. This 2.3:1 boy-to-girl ratio is consistent with the majority of previously reported estimates, which range from 2:1 to 3:1 in samples of preschool children with speech delay (Shriberg \& Kwiatkowski, 1994; but see also Shriberg et al., 1999, who reported a boy-to-girl ratio of 1.2:1 in 6-year-olds). Potential explanations for the higher percentage of boys with early speech delay include their relatively slower rates of physiological development and their greater susceptibility to neurological disease (Halpern, 1997; Naglieri \& Rojahn, 2001). Recent studies have also shown sex differences in frontal and temporal cortical areas during performance of fine motor and tactile tasks (Rescher \& Rappelsberger, 1996). Such differences could directly affect specific cognitive, linguistic, and motor processes that subserve the earliest stages 
of speech acquisition, although it is important to note that children's experiences may also differ by sex (Halpern, 1997; Leaper, Anderson, \& Sanders, 1998).

A second question concerns the extent to which the increased risk associated with positive family history reflects the impact of genetic versus environmental factors. Family aggregation studies have consistently shown a substantially greater prevalence of affected relatives among children with speech and language deficits than among children in control groups (for reviews, see Bishop, 2001; Felsenfeld et al., 1995; Felsenfeld \& Plomin, 1997; Stromswold, 1998). For children with speechlanguage disorders, previous studies have shown that the rate of disorders among first-degree relatives averages approximately 30\% (Felsenfeld \& Plomin, 1997; Lewis \& Freebairn, 1997; Lewis, Freebairn, \& Taylor, 2000a), a finding that is consistent with the results of the present study. Although recent molecular genetic studies have implicated specific genes in certain speech and language phenotypes (Bartlett et al., 2002; Lai et al., 2000; Lai, Fischer, Hurst, Vargha-Khadem, \& Monaco, 2001; Schick et al., 2002), familial aggregation alone does not provide sufficient evidence for a genetic cause of speech delay. As noted by Bishop (2001, p. 270), familial aggregation findings could be linked to cultural transmission variables including the abnormal speech patterns of affected relatives, or to environmental influences that are shared by family members.

Many questions remain concerning the ways sociodemographic variables influence children's speech-sound development. Maternal education less than high school is believed to be a general proxy for several socioeconomic variables that are consistently associated with a range of poor developmental outcomes including mental retardation (Chapman, Scott, \& Mason, 2002), reduced expressive language performance (Dollaghan et al., 1999), and social and behavioral problems (Adams, Hillman, \& Gaydos, 1994). There is now a substantial amount of evidence showing that maternal educational experience is significantly correlated with income, health, nutrition, home environment, and cognitive and language stimulation (Fujiura \& Yamaki, 2000; Satcher, 1995; Siegel, 1982; Smith, Brooks-Gunn, \& Klebanov, 1997; Zill, 1996). Although direct evidence is currently lacking, it is reasonable to hypothesize that deprivation in one or more of these areas could contribute to delays in speech development through various pathways. For example, the relatively lower amounts of language input provided to children by parents whose socioeconomic status is low (Hart \& Risley, 1995; Roberts, Burchinal, \& Durham, 1999) could result in less perceptual and motor experience with early phonological forms. At the same time, physiological or neurological impairments associated with inadequate health care and nutrition (Smith et al., 1997) or increased exposure to environmental toxins such as lead (Needleman, Schell, Bellinger, Leviton, \& Allred, 1990) in lowincome homes could plausibly delay or disrupt the acquisition of the processes involved in speech production.

Our results also demonstrate the additive impact of male sex, low maternal education, and family history of developmental communication disorder when these three variables occur in combination. Several investigators have proposed that developmental speech delay in young children cannot be attributed to a single factor, and that multifactorial approaches are required to estimate the cumulative risk for speech deficits (Paden, Matthies, \& Novak, 1989; Shriberg, Flipsen, et al., 2000). However, sample size limitations and research design constraints have precluded cumulative risk analyses in previous studies. To our knowledge, the present study is the first to report the aggregated risk of speech delay. Specifically, we found that a male child who had a positive family history of developmental communication disorder and whose mother did not graduate from high school was almost 8 times as likely to have speech delay at age 3 as a child who had none of these characteristics. These aggregate risk data are in accord with the hypothesis that the accumulation of risk factors rather than the influence of individual risks may pose the greatest threat to developmental outcome (Black \& Sonnenshein, 1993; Sameroff, Seifer, Barocas, Zax, \& Greenspan, 1987).

\section{Future Directions}

Although the present study addressed several risk variables, the sample did not include children who were at risk for developmental deficits on the basis of factors other than middle-ear disease. This precluded investigating the extent to which the risk variables identified here may interact with known threats to speech development such as oral-facial abnormalities, neurological dysfunction, cognitive deficits, and language impairments. It will also be important to examine the possibility that some variables may act as protective devices in the face of threats to speech development; for example, high maternal education (e.g., a college degree) has been shown to attenuate significantly the risk of poor 
developmental outcomes associated with both mental retardation and low birth weight (Camp, Broman, Nichols, \& Leff, 1998; Drews, Yeargin-Allsopp, Decoufle, \& Murphy, 1995).

Finally, most children with early speech delay are expected to achieve normal speech skills by early school age, given that the prevalence of speech delay in 6-year-olds is only 3.8\% (Shriberg et al., 1999) compared with the $15.6 \%$ we found in our sample of 3 -year-old children. Several studies have found that early speech disorders are related to both later reading and academic difficulties (e.g., Felsenfeld et al., 1995; Lewis et al., 2000a, 2000b). It will be important to examine the extent to which the risk factors we identified at age 3 become stronger or weaker predictors of those children whose speech delays persist into the early school years.

\section{References}

Adams, C., Hillman, N., \& Gaydos, G. (1994). Behavioral difficulties in toddlers: Impact of sociocultural and biological factors. Journal of Clinical Child Psychology, 23, 373-381.

Bartlett, C. W., Flax, J. F., Louge, M. W., Vieland, V. J., Bassett, A. S., Tallal, P., et al. (2002). A major susceptibility locus for specific language impairment is located on 13q21. American Journal of Human Genetics, 71, 45-55.

Bishop, D. V. M. (2001). Genetic and environmental risks for specific language impairment in children. The Philosophical Transactions of the Royal Society of London, 356, 369-380.

Black, M. M., \& Sonnenschein, S. (1993). Early exposure to otitis media: A preliminary investigation of behavioral outcome. Developmental and Behavioral Pediatrics, 14, 150155.

Camp, B. W., Broman, S. H., Nichols, P. L., \& Leff, M. (1998). Maternal and neonatal risk factors for mental retardation: Defining the "at risk" child. Early Human Development, 50, 159-173.

Chapman, D. A., Scott, K. G., \& Mason, C. A. (2002). Early risk factors for mental retardation: Role of maternal age and maternal education. American Journal of Mental Retardation, 107, 46-59.

Dollaghan, C. A., Campbell, T. F., Paradise, J. L., Feldman, H. M., Janosky, J. E., Pitcairn, D. N., et al. (1999). Maternal education and measures of early speech and language. Journal of Speech, Language, and Hearing Research, 42, 1432-1443.

Drews, C. D., Yeargin-Allsopp, M., Decoufle, P., \& Murphy, C. C. (1995). Variation in the influence of selected sociodemographic risk factors for mental retardation. American Journal of Public Health, 85, 329-334.

Felsenfeld, S., McGue, M., \& Broen, P. A. (1995). Familial aggregation of phonological disorders: Results from a 28-year follow-up. Journal of Speech and Hearing Research, $28,1091-1107$.
Felsenfeld, S., \& Plomin, R. (1997). Epidemiological and offspring analyses of developmental speech disorders using data from the Colorado Adoption Project. Journal of Speech, Language, and Hearing Research, 40, 778-791.

Fujiura, G. T., \& Yamaki, K. (2000). Trends in demography of childhood poverty and disability. Exceptional Children, 66, 187-199.

Halpern, D. F. (1997). Sex differences in intelligence: Implications for education. American Psychologist, 52, 1091-1102.

Harston, G., Nettelbladt, U., Schalen, L., Kalm, O., \& Prellner, K. (1993). Language development in children with recurrent otitis media during the first three years of life: Follow-up study from birth to seven years of age. Journal of Laryngology and Otology, 107, 407-412.

Hart, B., \& Risley, T. (1995). Meaningful differences in the everyday experience of young American children. Baltimore: Brooks.

Ingram, D. (1989). Phonological disability in children: Studies in disorders of communication (2nd ed.). San Diego, CA: Singular.

Lai, C. S., Fisher, S. E., Hurst, J. A., Levy. E. R., Hodgson, S., Fox, M., et al. (2000). The SPCH1 region on human 7q31: Genomic characterization of the critical interval and localization of translocations associated with speech and language disorder. American Journal of Human Genetics, $67,357-368$.

Lai, C. S., Fisher, S. E., Hurst, J. A., Vargha-Khadem, F., \& Monaco, A. P. (2001). A forkhead-domain gene is mutated in a severe speech and language disorder. Nature, 413, 519-523.

Lassman, F. M., Fisch, R. O., Vetter, D. K., \& LaBenz, E. J. (Eds.). (1980). Early correlates of speech, language, and hearing. Littleton, MA: PSG.

Leaper, C., Anderson, K. J., \& Sanders, P. (1998). Moderators of gender effects on parents' talk to their children: A meta-analysis. Developmental Psychology, 34, 3-27.

Leske, M. (1981). Prevalence estimates of communicative disorders in the United States: Speech disorders. ASHA, 23, 217-228.

Lewis, B. (1992). Pedigree analysis of children with phonology disorders. Journal of Learning Disabilities, 25, 586-597.

Lewis, B., Ekelman, B., \& Aram, D. (1989). A familial study of severe phonological disorders. Journal of Speech and Hearing Research, 32, 713-724.

Lewis, B., \& Freebairn, L. (1997). Speech production skills of nuclear family members of children with phonology disorders. Language and Speech, 41, 45-61.

Lewis, B., Freebairn, L., \& Taylor, H. G. (2000a). Follow-up of children with early expressive phonology disorders. Journal of Learning Disabilities, 33, 433-444.

Lewis, B., Freebairn, L., \& Taylor, H. G. (2000b). Academic outcomes in children with histories of speech sound disorders. Journal of Communication Disorders, 33, 11-30.

McSweeny, J. L., \& Shriberg, L. D. (1995). Segmental and suprasegmental transcription reliability (Tech. Rep. No. 2). 
Madison, WI: University of Wisconsin-Madison Waisman Center on Mental Retardation and Human Development, Phonology Project.

Naglieri, J. A., \& Rojahn, J. (2001). Gender differences in planning, attention, simultaneous, and successive (PASS) cognitive process and achievement. Journal of Educational Psychology, 93, 430-437.

Needleman, H. (1977). Effects of hearing loss from early recurrent otitis media on speech and language development. In B. Jaffe (Ed.), Hearing loss in children (pp.640 649). Baltimore: University Park Press.

Needleman, H. L., Schell, A., Bellinger, D., Leviton, A., \& Allred, E. N. (1990). The long-term effects of exposure to low doses of lead in childhood: An 11-year follow-up report. New England Journal of Medicine, 322, 83-88.

Paden, E. P., Matthies, M. L., \& Novak, M. A. (1989). Recovery from OME-related phonologic delay following tube placement. Journal of Speech and Hearing Disorders, 54, 94-100.

Paradise, J. L., Dollaghan, C. A., Campbell, T. F., Feldman, H. M., Bernard, B. S., Colborn, D. K., et al. (2000). Language, speech sound production, and cognition in 3year-old children in relation to otitis media in their first three years of life. Pediatrics, 105, 1119-1130.

Paradise, J. L., Feldman, H. M., Campbell, T. F., Dollaghan, C. A., Colborn, D. K., Bernard, B. S., et al. (2001). Effects of early or delayed insertion of tympanostomy tubes for persistent otitis media on developmental outcomes at the age of three years. New England Journal of Medicine, $344,1179-1187$.

Paradise, J. L., Rockette, H. E., Colborn, D. K., Bernard, B. S., Smith, C. G., Kurs-Lasky, M., et al. (1997). Otitis media in 2253 Pittsburgh-area infants: Prevalence and risk factors during the first two years of life. Pediatrics, 99, 318-333.

Peckham, C. S. (1973). Speech defects in a national sample of children aged seven years. British Journal of Disorders of Communication, 8, 2-8.

Rescher, B., \& Rappelsberger, P. (1996). EEG changes in amplitude and coherence during a tactile task in females and males. Journal of Psychophysiology, 10, 161172.

Roberts, J. E., Burchinal, M., \& Durham, M. (1999). Parents' report of vocabulary and grammatical development of African American preschoolers: Child and environmental associations. Child Development, 70, 92-106.

Roberts, J. E., Burchinal, M. R., Koch, M. A., Footo, M. M., \& Henderson, F. W. (1988). Otitis media in early childhood and its relationship to later phonological development. Journal of Speech and Hearing Disorders, 34, 1158-1168.

Sackett, D. L., Haynes, R. B., Guyatt, G. H., \& Tugwell, P. (1991). Clinical epidemiology: A basic science for clinical medicine (2nd ed.). Boston: Little, Brown.

Sameroff, A. J., Seifer, R., Barocas, R., Zax, M., \& Greenspan, S. (1987). Intelligence quotient scores of 4-year-old children: Social-environmental risk factors. Pediatrics, 79, 343-350.
Satcher, D. (1995). Annotation: The sociodemographic correlates of mental retardation. American Journal of Public Health, 85, 304-306.

Schick, J. H., Kundtz, A. M., Tiwari, H. K., Taylor, H. G., Freebairn, L. A., Shriberg, L. D., et al. (2002, July). Evidence of linkage with chromosome 7q31 markers in sib pairs with speech but not language disorders. Paper presents at the 2002 Joint Conference of the 9th International Congress for the Study of Child Language and the Symposium on Research in Child Language Disorders, Madison, WI.

Scott, K. G., Mason, C. A., \& Chapman, D. A. (1999). The use of epidemiological methodology as a means of influencing public police. Child Development, 70, 12631272.

Shriberg, L. D. (1980). Developmental phonological disorders. In T. J. Hixon, L. D. Shriberg, \& J. S. Saxman (Eds.), Introduction to communicative disorders (pp. 262 309). Englewood Cliffs, NJ: Prentice Hall.

Shriberg, L. D. (1993). Four new speech and prosody-voice measures for genetics research and other studies in developmental phonological disorders. Journal of Speech and Hearing Research, 36, 105-140.

Shriberg, L. D. (1994). Five subtypes of developmental phonological disorders. Clinics in Communication Disorders, 4, 38-53.

Shriberg, L. D., Allen, C. T., McSweeny, J. L., \& Wilson, D. L. (2000). PEPPER: Programs to Examine Phonetic and Phonologic Evaluation Records. [Computer software]. Madison: Waisman Center on Mental Retardation and Human Development, University of Wisconsin-Madison.

Shriberg, L. D., Austin, D., Lewis, B. A., McSweeny, J. L., \& Wilson, D. L. (1997). The Speech Disorders Classification System (SDCS): Extensions and lifespan reference data. Journal of Speech, Language, and Hearing Research, 40, 723740 .

Shriberg, L. D., Flipsen, P., Thielke, H., Kwiatkowski, J., Kertoy, M. K., Katcher, M. L., et al. (2000). Risk for speech disorder associated with early recurrent otitis media with effusion: Two retrospective studies. Journal of Speech, Language, and Hearing Research, 43, 79-99.

Shriberg, L. D., Friel-Patti, S. F., Flipsen, P., \& Brown, R. (2000). Otitis media, fluctuant hearing loss, and speechlanguage outcomes: A preliminary structural equation model. Journal of Speech, Language, and Hearing Research, 43, 100-120.

Shriberg, L. D., \& Kwiatkowski, J. (1982). Phonological disorders I: A diagnostic classification system. Journal of Speech Hearing Disorders, 47, 226-270.

Shriberg, L. D., \& Kwiatkowski, J. (1994). Developmental phonological disorders I: A clinical profile. Journal of Speech and Hearing Research, 37, 1100-1126.

Shriberg, L. D., Kwiatkowski, J., \& Hoffman, K. A. (1984). A procedure for phonetic transcription by consensus. Journal of Speech and Hearing Research, 27, 456-465.

Shriberg, L. D., \& Smith, A. J. (1983). Phonological correlates of middle-ear involvement in speech-delayed 
children: A methodological note. Journal of Speech and Hearing Research, 26, 293-297.

Shriberg, L. D., Tomblin, J. B., \& McSweeny, J. L. (1999). Prevalence of speech delay in 6-year-old children and comorbidity with language impairment. Journal of Speech, Language, and Hearing Research, 42, 1461-1481.

Siegel, L. (1982). Reproductive, perinatal, and environmental factors as predictors of the cognitive and language development of preterm and full-term infants, Child Development, 53, 963-973.

Silva, P. A., Chalmers, D., \& Stewart, I. (1986). Some audiological, psychological, educational and behavioral characteristics of children with bilateral otitis media with effusion. Journal of Learning Disabilities, 19, 165-169.

Silva, P. A., Justin, C., McGee, R., \& Williams, (1984). Some developmental and behavioral characteristics of sevenyear-old children with delayed speech development. British Journal of Disorders of Communication, 19, 147-154.

Silva, P. A., Kirkland, C., Simpson, A., Stewart, I. A., \& Williams, S. M. (1982). Some developmental and behavioral problems associated with bilateral otitis media with effusion. Journal of Learning Disabilities, 15, 417-421.

Smith, J., Brooks-Gunn, J., \& Klebanov, P. (1997). Consequences of living in poverty for young children's cognitive and verbal ability and early school achievement. In G. Duncan \& J. Brooks-Gunn (Eds.), Consequences of growing up poor (pp. 132-189). New York: Russell Sage Foundation.
Streiner, D. L. (1998). Risky business: Making sense of estimates of risk. The Canadian Journal of Psychiatry, 43, 411-415.

Stromswold, K. (1998). Genetics of spoken language disorders. Human Biology, 70, 297-324.

Teele, D. W., Klein, J. O., Chase, C., Menyuk, P., \& Rosner, B. A. (1990). Otitis media in infancy and intellectual ability, school achievement, speech, and language at 7 years. Journal of Infectious Disease, 162, 685-694.

Tomblin, J. B. (1989). Familial concentration of developmental language impairment. Journal of Speech and Hearing Disorders, 54, 287-295.

Tomblin, J. B., Hardy, J. C., \& Hein, H. A. (1991). Predicting poor communication status in preschool children using risk factors present at birth. Journal of Speech and Hearing Research, 34, 1096-1105.

Walter, S. D. (2000). Choice of effect measure for epidemiological data. Journal of Epidemiology, 53, 931939.

Winitz, H., \& Darley, F. (1980). Speech production. In P. LaBenz \& A. LaBenz (Eds.), Early correlates of speech, language and hearing (pp.232-265). Littleton, MA: PSG.

Zhang, J., \& Wu, K. F. (1998). What's the relative risk? A method of correcting the odds ratio in cohort studies of common outcomes. Journal of the American Medical Association, 280, 1690-1691.

Zill, N. (1996). Parental schooling and children's health. Public Health Reports, 111, 34-43. 